\title{
Analysis of Mechanical and Acoustic Emission Characteristics of Rock Materials with Double-Hole Defects Based on Particle Flow Code
}

\author{
Qi Zhang $\mathbb{D},{ }^{1,2}$ Xiao Wang $\mathbb{D},{ }^{1}$ Long-gang Tian, ${ }^{1}$ and Dong-mei Huang $\mathbb{D}^{3}$ \\ ${ }^{1}$ School of Civil Engineering, Southeast University, Nanjing 210096, China \\ ${ }^{2}$ State Key Laboratory for Geomechanics and Deep Underground Engineering, China University of Mining \& Technology, \\ Xuzhou 221116, China \\ ${ }^{3}$ State Key Laboratory of Mining Disaster Prevention and Control Co-founded by Shandong Province and the Ministry of Science \\ and Technology, Shandong University of Science and Technology, Qingdao 266590, China \\ Correspondence should be addressed to Xiao Wang; wangchxizo@163.com
}

Received 11 February 2018; Accepted 5 July 2018; Published 1 October 2018

Academic Editor: Ivo Caliò

Copyright ( 2018 Qi Zhang et al. This is an open access article distributed under the Creative Commons Attribution License, which permits unrestricted use, distribution, and reproduction in any medium, provided the original work is properly cited.

\begin{abstract}
There are a lot of fissures, holes, and other defects in the formation of natural rocks. Under the influence of the external loads, these defects may cause engineering problems. Therefore, it is of great significance to analyze the characteristics of damage evolution of the defective rocks. In the study, the double-hole defective rocks with different angles of the center connection line are considered and the numerical models are established firstly. Then the mechanical behavior and acoustic emission (AE) characteristics are analyzed systematically. Finally the laws of damage evolution of the defective rock materials are investigated based on the AE characteristics. The research results show that the stress-strain behavior of the defective rocks can be divided into elastic stage, plastic stage and failure stages. The characteristics of acoustic emission evolution and laws of damage evolution are closely related to the stress-strain relationship. The elastic modulus of the double-hole defective rocks is similar with different angles of the center connection line, but the peak strength is different. The shape of the peak strength of these defective rocks is a $\mathrm{W}$ type owing to the different failure modes. The influences of different angles of the center connection line on the characteristics of $\mathrm{AE}$ evolution include the maximum events number, the strain value of the initial AE events and the maximum AE events, and the strain range of the serious AE events. Different angles of the center connection line have different influences on the laws of damage evolution of the double-hole defective rocks.
\end{abstract}

\section{Introduction}

As the main medium of mine, tunnel, hydropower, and other engineering, the stability of rock is very important to the safety of the project [1-3]. Under the influence of geological process, natural rock materials contain a large number of holes, joints, fractures and other defects, which lead to the heterogeneity and anisotropy of the rock mechanical behaviors $[4,5]$. Therefore, analysis on the characteristics of the damage evolution of the defective rocks is of great significance for the prevention and control of rock mass engineering disasters.
Many researches have conducted several investigations on the characteristics of damage evolution of defective rocks. Justo et al. [6] used the rock mass classification systems to estimate the modulus and strength of jointed rock. Lee and Jeon [7] conducted a series of uniaxial compression tests on Poly Methyl MethAcrylate (PMMA), Diastone, and Hwangdeung granite to study the coalescence behavior of two nonparallel flaws, which consist of a horizontal flaw and an underlying inclined flaw. Wang and Tian [8] investigated the influence of the combined fracture holes on the mechanical and characteristics of crack evolution in coal by means of microparticle flow code. Sammis and Ashby [9] 
used the plate specimens containing a single hole of the same size or an array of holes with various diameters to study the interaction of growing cracks with the surfaces of the specimen and the interaction with secondary cracks. Steen et al. [10] carried out both experimental and numerical tests to analyze the damage pattern for a loaded disc with eccentric holes. Li et al. [11] discussed the dynamic compressive strength and characteristics of crack propagation of specimens with prefabricated holes. Han et al. [12] carried out the uniaxial compression tests for the sandstone samples of two circular holes with different diameters and different geometries of holes. The interaction mechanism between two holes and the influence of holes on rock mechanical behavior were obtained. Jiang et al. [13] implemented a joint fractal dimension into the numerical modeling of a jointed rock mass to assess the behaviors of deformation of rock mass under opening. The generated joint network has various fractal dimensions and models different joint traces, space, and gaps.

Existing researches play a positive role in analyzing the damage mechanism of defective rocks. However, the cognition of the damage mechanism of the defective rock materials is not enough to well solve the engineering problems. Therefore, more conditional forms of defective rock damage characteristics need to be studied. In the study, the double-hole defective rocks with different angles, which are between the center connection line of the two holes and the horizontal plane, are considered. The numerical defective rock models are established in Section 2 firstly, and then the mechanical behavior and AE characteristics are analyzed in Section 3. Finally, the laws of damage evolution of defective rocks are investigated based on the AE characteristics in Section 4.

\section{Numerical Modeling of Double-Hole Defective Rocks}

2.1. Particle Flow Code (PFC). In 1979, Cundall and Strack [14] established particle flow code (PFC) theory using the discrete element method. The basic compositions of the PFC model are particles and bonds, and the geometrical and mechanical properties of the particles and bonds determined the macroscopic mechanical properties of the models. The particle is a disk in the two-dimensional model and a ball in the three-dimensional model. There are two kinds of modes of the bonds, named contact bond (CB), and parallel bond (PB) $[8,15,16]$. The CB model (Figure 1(a)) has little resistance to the moment induced by particle rotation or shearing while PB model (Figure 1(b)) can resist to such particle movements since $\mathrm{PB}$ model is acting like a beam that resists the bending moment occurring within the bonded area $[8,17]$. In this study, the models of the double-hole defective rocks are built by using the parallel bond.

2.2. Acoustic Emission Simulation by PFC. When the rock numerical models are established, the normal and tangential bonding strength can directly reflect the macroscopic strength of the rock. Under the influence of the loading, the bond fractures create microcracks in the rock specimen when the stress intensity transmitted between the particles exceeds the bonding strength between the particles [18]. As the microcrack propagating in the rock specimen, the damage energy is rapidly released as acoustic waves, which is the AE phenomenon $[19,20]$. Therefore, the AE events can be simulated by counting the particle bond breaking number during the numerical tests. Due to the limitation of computing capacity, the particle size and particle number of PFC2D cannot reach the level of mechanical response directly to real macroscopic rock, but the mechanical law reflected is very helpful for understanding the AE phenomenon of rocks [21].

2.3. Parameters of Numerical Rock Models. In PFC theory, the macromechanical property of the rock model is determined by the micromechanical property of the particles and bonds. However, these parameters cannot be directly derived directly from in-situ tests and indoor experiments. Therefore, the microscopic parameters selection and verification are needed before the numerical simulation [8]. Usually, the microparameters of PFC rock models are calibrated by simulating the uniaxial compression experiments $[17,22]$. During the process of calibration, the microparameters of the particles and bonds are adjusted many times through "trial and error" method until these parameters can better reflect the mechanical properties of the real rocks [22-24]. The uniaxial compression calibration procedure of PFC (version 5.0) is shown in Figure 2.

Based on the uniaxial compression laboratory tests of sandstone [12], three PFC numerical models (I-III) are established, as shown in Figure 3. The model I is corresponding with the real intact rock specimen, and the other two models of II and III are corresponding with the test scheme A45-1 and B20-1, respectively. The size of the numerical intact rock model is $80 \mathrm{~mm}$ (length) $\times 160 \mathrm{~mm}$ (height), and the total number of particles is 14,456 . The angle $\alpha$, which is between the center connection line of the two holes and the horizontal plane, is $45^{\circ}$. The distance $(L)$ between the centers of two holes is $25 \mathrm{~mm}$, and the diameter of the center hole $(D)$ is $20 \mathrm{~mm}$. The diameter of the secondary hole $(d)$ in the model I and the model III is $6 \mathrm{~mm}$ and $20 \mathrm{~mm}$, respectively. The load of the numerical models is applied by moving the upper wall and the loading rate is $0.0017 \mathrm{~mm} / \mathrm{s}$. All conditions of the numerical tests are same as the laboratory tests. Through "trial and error" method with repeated check comparisons, the physical mechanical parameters listed in Table 1 can well reflect the macroscopic mechanical property of the real sandstone. The stress-strain curves (Figure 4) and the failure modes (Figure 5) of PFC models are in good agreement with the laboratory results of real sandstone.

2.4. Numerical Double-Hole Defective Rock Models. In order to study the characteristics of damage evolution of the double-hole defective rocks with different center connection line angle, seven PFC numerical rock models with the same $L, D$, and $d$ are built with different $\alpha$, as shown in Figure 6 . 


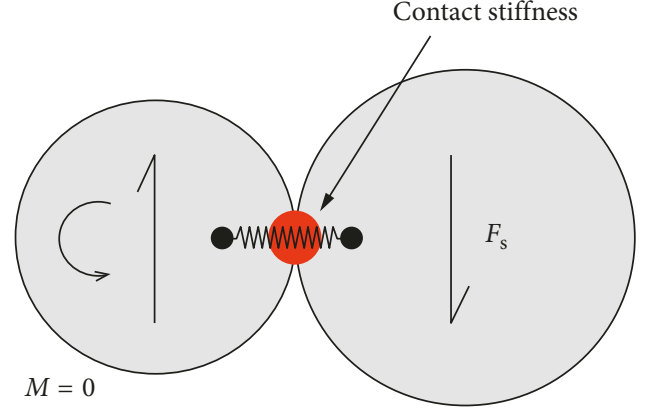

(a)

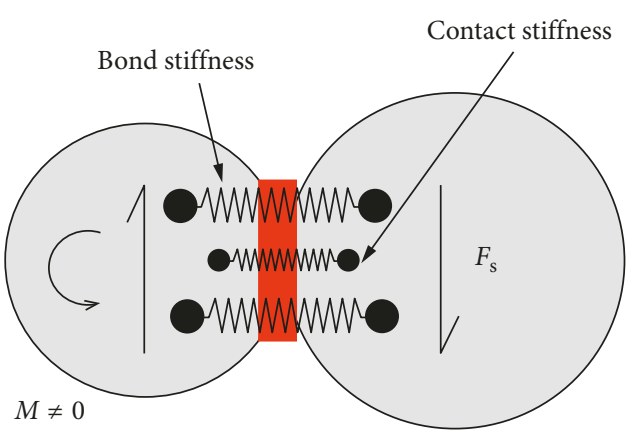

(b)

FIgURE 1: Cohesive model and its micromechanical behavior schematic diagram [8, 17]. (a) Contact bond model. (b) Parallel bond model.

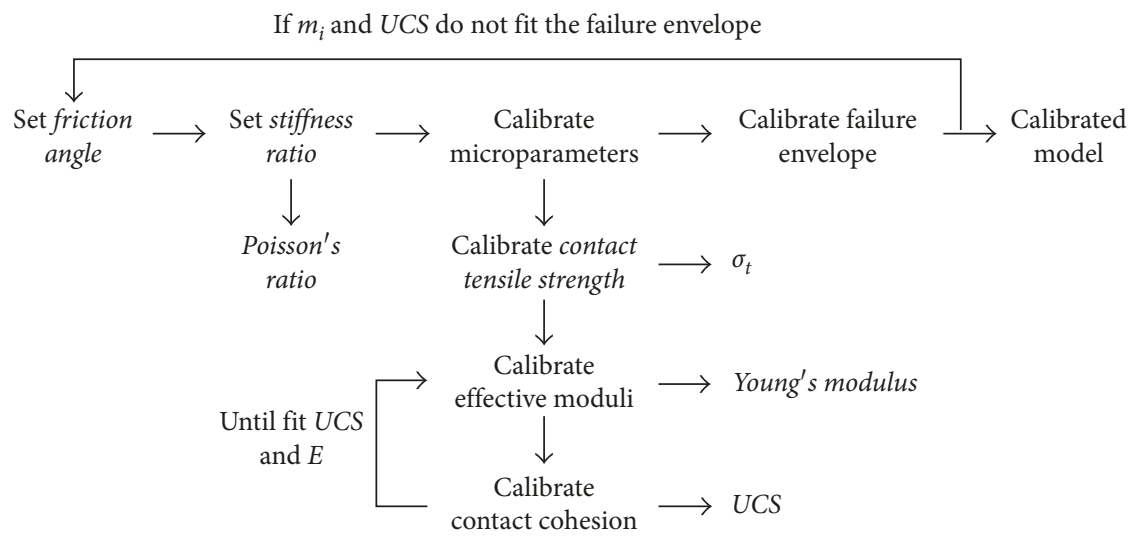

FIGURE 2: Uniaxial compression calibration procedure defined by Itasca $[8,15,22]$.

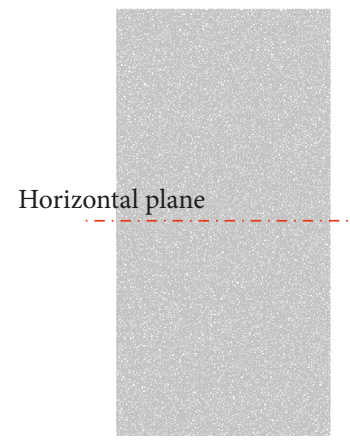

(a)

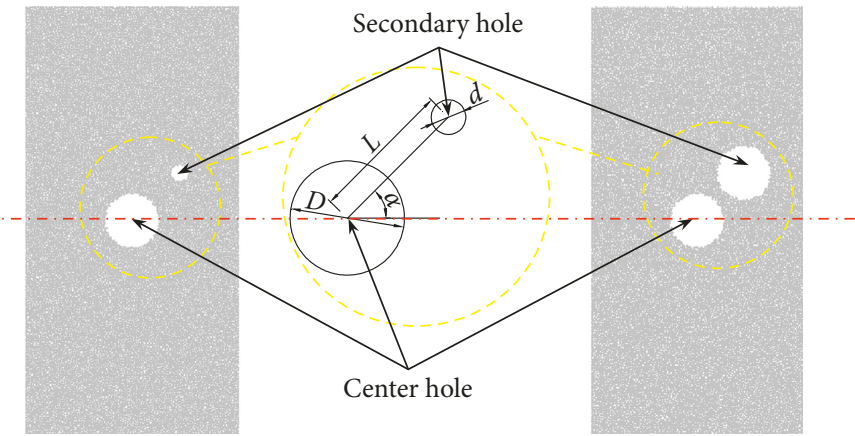

(c)

FIGURE 3: Sandstone numerical models based on PFC. (a) Numerical model I: Intact rock without center and secondary holes. (b) Numerical model II: Double-hole defective rock with a center hole $(D=20 \mathrm{~mm})$ and secondary hole $(d=5 \mathrm{~mm})$. (c) Numerical model III: Double-hole defective rock with a center hole $(D=20 \mathrm{~mm})$ and secondary hole $(d=20 \mathrm{~mm})$.

TABle 1: Physico-mechanical parameters of sandstone model based on PFC.

\begin{tabular}{lccc}
\hline Parameter & Value & Parameter & Value \\
\hline Minimum particle diameter $(\mathrm{mm})$ & 0.4 & Porosity & 0.1 \\
Particle diameter ratio & 1.5 & Parallel bond friction angle $\left(^{\circ}\right)$ & 38 \\
Density $\left(\mathrm{kg} / \mathrm{m}^{3}\right)$ & 2440 & Parallel bond tensile strength $(\mathrm{MPa})$ & Normal critical damping ratio \\
Contact modulus of the particle $(\mathrm{GPa})$ & 4.0 & Parallel bond cohesive force $(\mathrm{MPa})$ & 0.5 \\
Parallel bond deformation modulus $(\mathrm{GPa})$ & 27 & Stiffness ratio & 39 \\
Contact bond gap $(\mathrm{mm})$ & 0.05 & & 1.0 \\
\hline
\end{tabular}




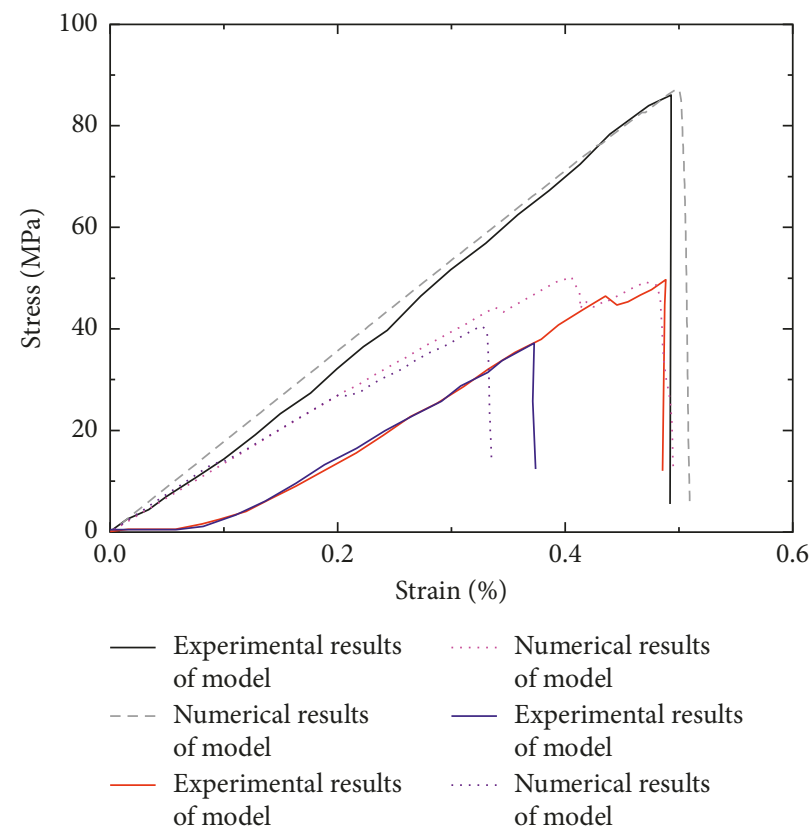

FIGURE 4: Stress-strain curves of experimental results [12] and numerical results.

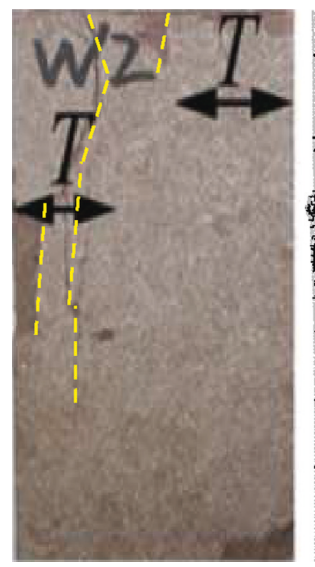

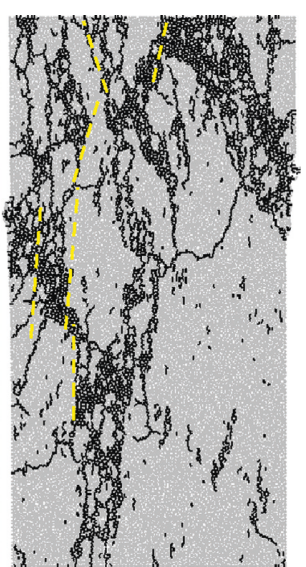

(a)
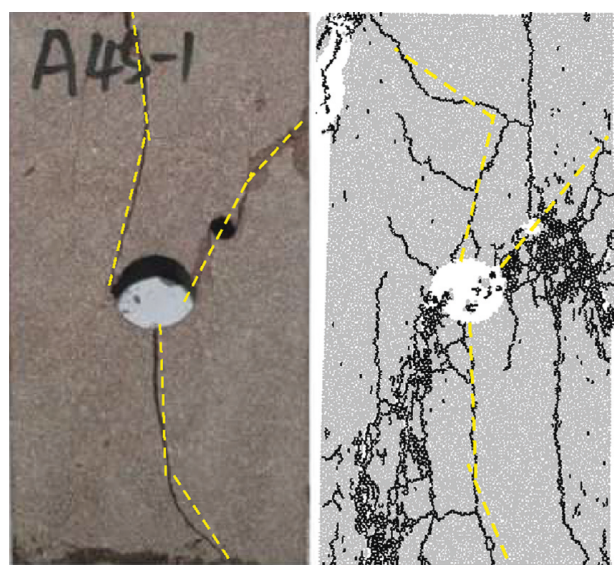

(b)

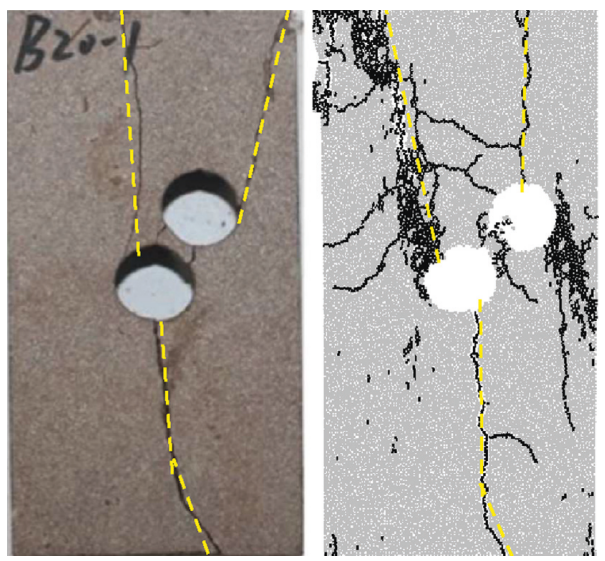

(c)

FIgURE 5: Failure modes of experimental specimens [12] and numerical models. (a) Model I. (b) Model II. (c) Model III. 


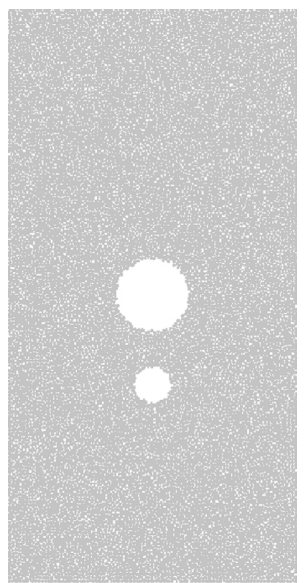

(a)

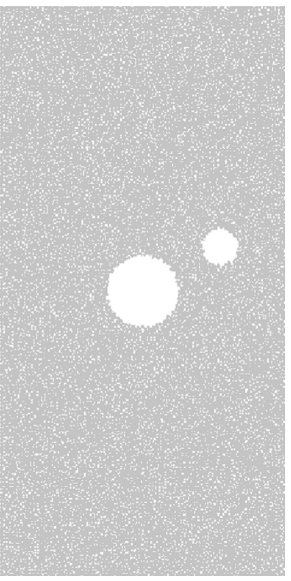

(e)

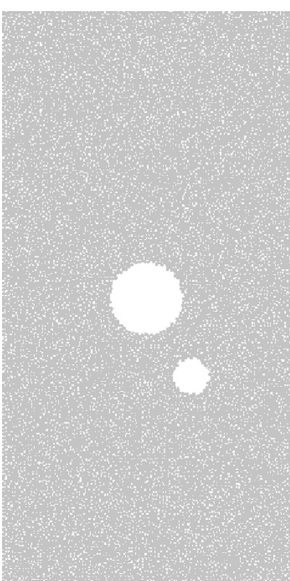

(b)

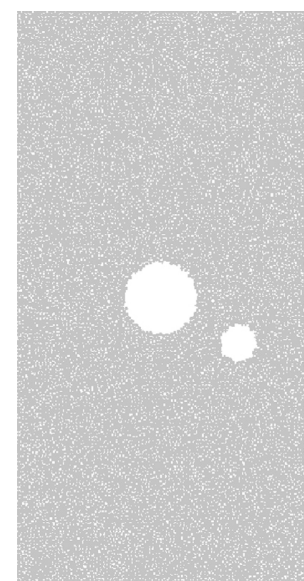

(c)

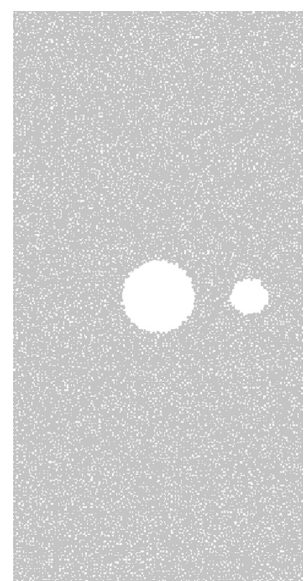

(d)

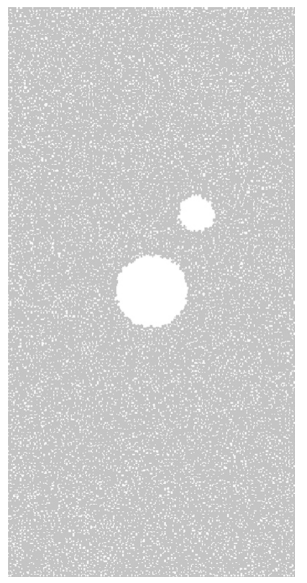

(f)

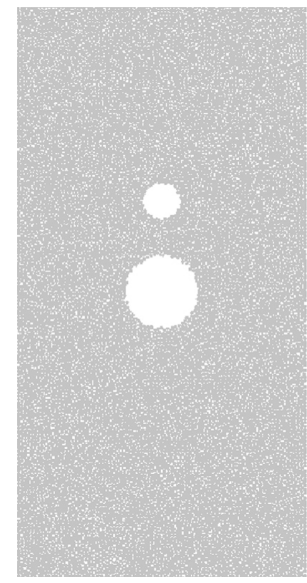

(g)

Figure 6: Numerical models of double-hole defective rock with different $\alpha$. (a) $\alpha=-90^{\circ}$, (b) $\alpha=-60^{\circ}$, (c) $\alpha=-30^{\circ}$, (d) $\alpha=0^{\circ}$, (e) $\alpha=30^{\circ}$, (f) $\alpha=60^{\circ}$, and (g) $\alpha=90^{\circ}$.

These models are firstly established as intact rock based on the parameters listed in Table 1. Then some balls of the intact rock models are deleted to form the double-hole defective rocks. There are seven kinds of the double-hole defective rock with different $\alpha$, which are $-90^{\circ},-60^{\circ},-30^{\circ}, 0^{\circ}, 30^{\circ}, 60^{\circ}$, and $90^{\circ}$. It is assumed that the positive value of $\alpha$ is along the counter clockwise direction. $L, D$, and $d$ of these double-hole defective models are fixed in $25 \mathrm{~mm}, 20 \mathrm{~mm}$, and $10 \mathrm{~mm}$. Loads are controlled by applying a compress displacement at the top wall of the specimen, with the rate of $0.0017 \mathrm{~mm} / \mathrm{s}$. The numerical tests will be ended until residual stress of the numerical specimens reached $10 \%$ of the peak strength controlling by the FISH language.

\section{Numerical Test Results Analysis}

3.1. Mechanical Properties. Figures 7 and 8 show the stressstrain and peak strength- $\alpha$ relationship curves of the doublehole defective rocks. It should be explained that the stressstrain curves refer to the average stress-strain behaviors of the whole specimen, rather than that of one part area of the specimen. The stress-strain of the defective rocks can be divided into three stages, which are elastic stage, plastic stage, and failure stage. Owing to that the particles of PFC rock models are rigid and there is no initial damage in the models, the stress-strain curves of the numerical rock models have not the closure stage at the beginning of the elastic stage such as the real rocks. PFC models eliminated the discreteness in the real rock and are more conducive to the study of the influence of the double-hole defects on mechanical properties of the rocks.

It can be seen from these two figures that as $\alpha$ varyies from $-90^{\circ}$ to $0^{\circ}$ and form $90^{\circ}$ to $0^{\circ}$, the peak strength of rocks is decreasing firstly and then increasing. As the $\alpha$ increasing from $-90^{\circ}$ to $90^{\circ}$, the peak strength of the defective rocks is 64.05 MPa, 52.40 MPa, 44.63 MPa, 52.79 MPa, $45.58 \mathrm{MPa}$, $53.43 \mathrm{MPa}$, and $65.21 \mathrm{MPa}$, respectively. The shape of the peak strength- $\alpha$ curve is a $\mathrm{W}$ type or an approximately symmetric $\sqrt{ }$ type, as shown in Figure 8 . It is because that the secondary hole of double-hole defective rock is symmetric to the horizontal plane which is along the direction when $\alpha$ is $0^{\circ}$. The symmetry of the defects leads to the symmetry of peak strength. The peak strength of the defective double-hole rocks when $\alpha$ is positive is higher than that when $\alpha$ is negative, even the same absolute value. The differences of the peak strength are decreasing as the absolute value of $\alpha$ from 
$90^{\circ}$ to $0^{\circ}$, which are $1.16 \mathrm{MPa}, 1.03 \mathrm{MPa}$, and $0.95 \mathrm{MPa}$, respectively. The reason is the loads applied by moving the top wall and the secondary hole near the loading wall, which has a boundary effect partly.

With different $\alpha$, the elastic modulus of the double-hole defective rocks is similarly and about $15.59 \mathrm{GPa}$. However, the stress-strain characteristics are quite discrete after the peak strength. Along with decreasing of the absolute value of $\alpha$, the post peak stress-strain curves change from smoothness with one peak to fluctuate with several peaks. For example, when $\alpha$ is $-90^{\circ}$, the stress-strain curve has one peak and suddenly drops down to the minimum value after the peak. But the stress-strain curve of the double-hole defective rock with $\alpha$ of $-30^{\circ}$ has three peaks and displays as a sawtooth shape.

By comparing the failure modes (Figure 9), several common phenomena can be concluded, especially the defective double-hole rocks with the symmetrical secondary holes to the horizontal axis. When the absolute value of $\alpha$ is $90^{\circ}$, the failure modes of the double-hole defective rock are symmetrical to the horizontal axis or the longitudinal axis. There is a huge penetrating fracture through the center hole. The fractures of the rocks are obviously an $\mathrm{X}$ type without overlying the secondary hole. Owing to that the secondary hole is not affected by the main fracture, the peak strength of these two defective rock specimens is higher than the others.

When the absolute values of $\alpha$ are $60^{\circ}$ and $30^{\circ}$, the failure modes of the double-hole defective rock are approximately symmetrical to the horizontal axis and the main fractures are through the double holes. The failure shape is a Y type when the absolute value of $\alpha$ is $60^{\circ}$ and is a $U$ type when the absolute value of $\alpha$ is $30^{\circ}$. When $\alpha$ is $0^{\circ}$, the shape of the failure mode shows a $\mathrm{V}$ type. The secondary hole plays an important effect on the peak strength of the defective rock mass.

3.2. Acoustic Emission Characteristics. Figure 10 shows the curves of stress-strain-AE events of the double-hole defective rocks with different $\alpha$. It can be seen from the figures that the evolutionary characteristics of AE events are closely related to the stress-strain relationship. When the stressstrain behavior is in the elastic stage, the number of $\mathrm{AE}$ events is very little. When the stress-strain behavior is in the plastic stage, the number of AE events increases and shows an incidental characteristic. When the stress-strain behavior is in the failure stage, the number of $\mathrm{AE}$ events reaches the peak and falls quickly, which means that the double-hole defective rock has damaged greatly in this period.

The influence of different $\alpha$ on the AE characteristics is described as follows.

(1) It affects the maximum AE event number. Apart from the maximum AE event number of double-hole defective rock with $\alpha$ equal to $0^{\circ}$, the maximum AE event number of these defective rocks decreases with the decreasing of the absolute value of $\alpha$. When $\alpha$ is less than or equal to $0^{\circ}$, the maximum $\mathrm{AE}$ event number is 579,307 , and 244 . And when $\alpha$ is bigger than or equal to $0^{\circ}$, the maximum $\mathrm{AE}$ event number

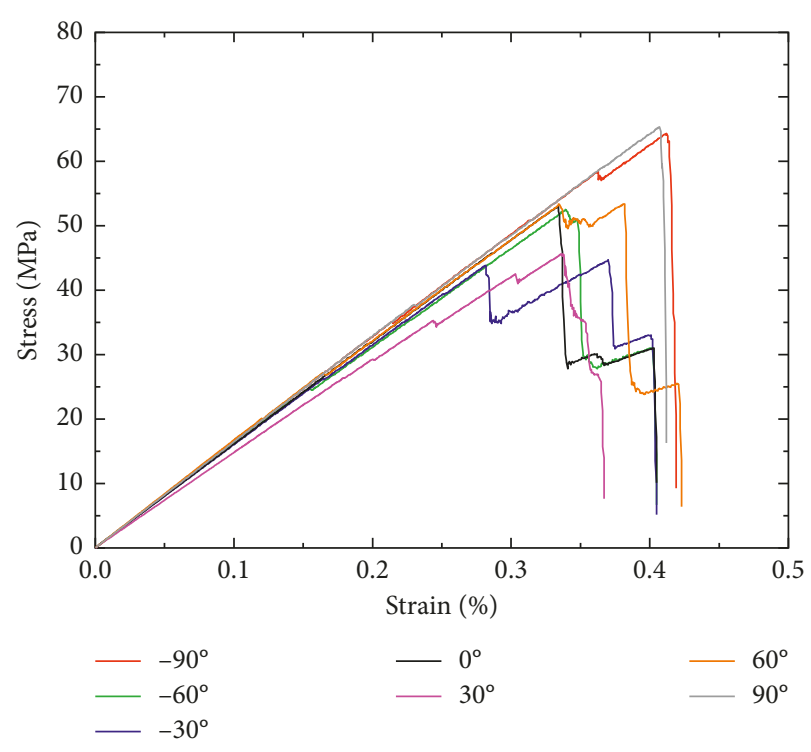

FIGURE 7: Stress-strain curves of numerical models of double-hole defective rock with different $\alpha$.

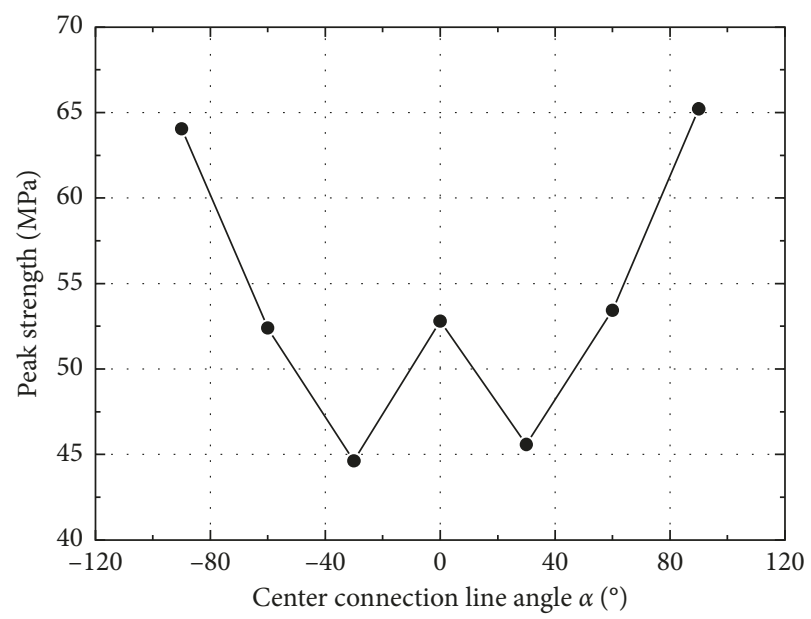

Figure 8: Peak strength of numerical double-hole defective rocks with different $\alpha$.

is 498,296 , and 237 . The evolutionary characteristic of the maximum event number of AE with different $\alpha$ is similarly with the change of the peak strength of the double-hole defective rocks. However, when the absolute value of $\alpha$ is same, the maximum AE event number of the defective rocks with $\alpha$ greater than $0^{\circ}$ are generally larger than that of the defective rocks with $\alpha$ less than $0^{\circ}$.

(2) It influences the strain values of the initial AE event and the maximum AE event. As $\alpha$ is from $-90^{\circ}$ to $90^{\circ}$, the strain values of the initial AE event are $0.196 \%$, $0.097 \%, 0.107 \%, 0.178 \%, 0.104 \%, 0.091 \%$, and $0.170 \%$ and the strain values of the maximum AE event are $0.419 \%, 0.406 \%, 0.405 \%, 0.404 \%, 0.365 \%, 0.383 \%$, and $0.411 \%$. Apart from the strain value of doublehole defective rock when $\alpha$ is equal to $0^{\circ}$, the strain values of the initial $\mathrm{AE}$ event and the maximum $\mathrm{AE}$ 


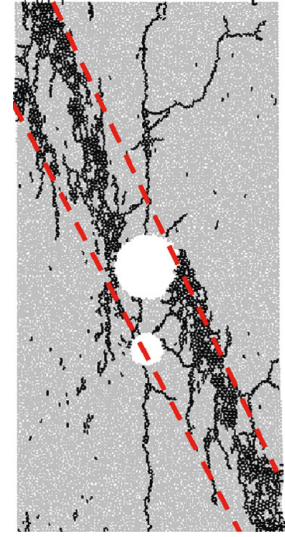

(a)

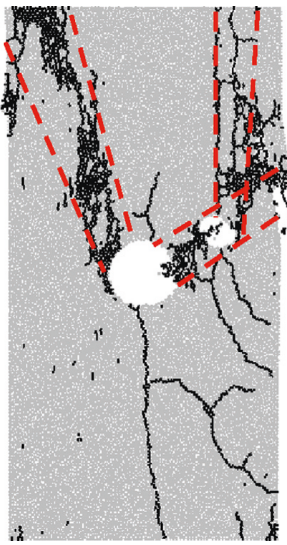

(e)

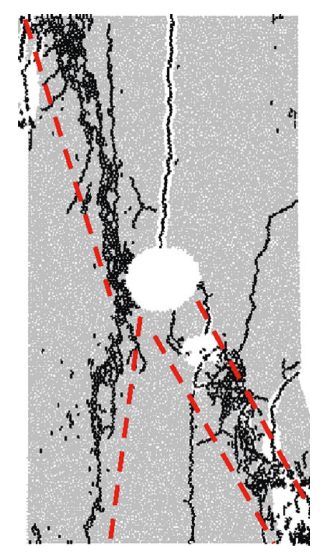

(b)

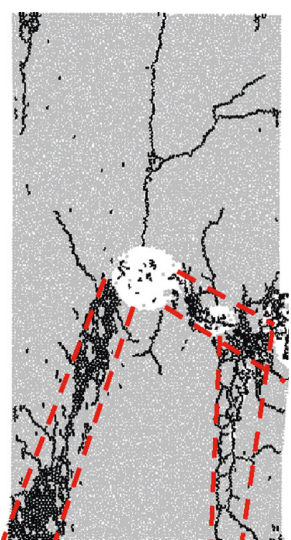

(c)

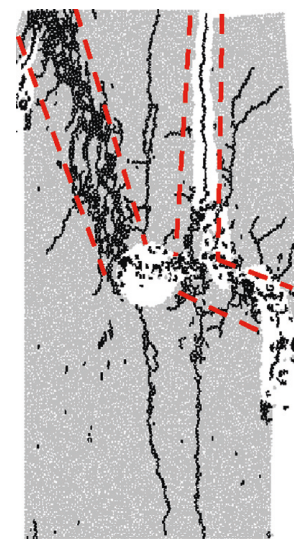

(d)

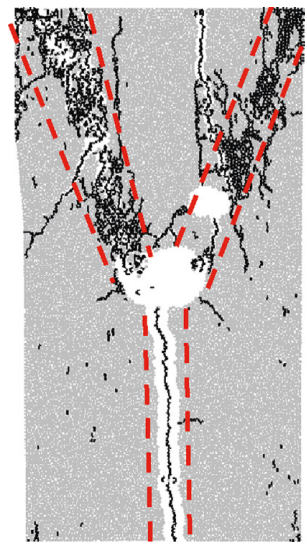

(f)

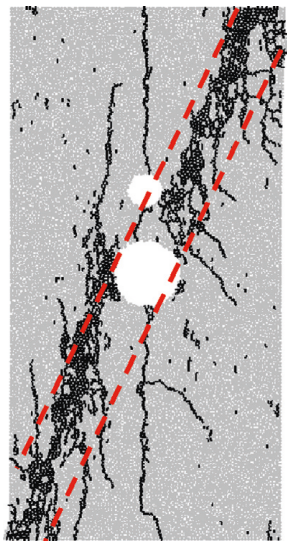

(g)

Figure 9: Failure modes of numerical models of double-hole defective rocks with different $\alpha$. (a) $\alpha=-90^{\circ}$, (b) $\alpha=-60^{\circ}$, (c) $\alpha=-30^{\circ}$, (d) $\alpha=0^{\circ}$, (e) $\alpha=30^{\circ}$, (f) $\alpha=60^{\circ}$, and (g) $\alpha=90^{\circ}$.

event of these defective rocks are decreasing with decrease of the absolute value of $\alpha$. The strain values of the initial $\mathrm{AE}$ event and the maximum $\mathrm{AE}$ event are almost equally when the absolute value of $\alpha$ is the same. The strain values of the double-hole defective rocks when $\alpha$ is positive are less than that of the defective rocks when $\alpha$ is negative. However, the strain values of the maximum $\mathrm{AE}$ event of the double-hole defective rocks when $\alpha$ is positive are larger than that of the defective rocks when $\alpha$ is negative.

(3) It influences the strain ranges of the drastic $\mathrm{AE}$ events. Apart from the strain range of the drastic AE events of the rock with $\alpha$ of $0^{\circ}$, the strain range of the drastic $\mathrm{AE}$ events increases with the decreasing of the absolute value of $\alpha$. For $\alpha$ of $-90^{\circ}$ to $-30^{\circ}$, the strain ranges of the drastic $\mathrm{AE}$ events are $0.059 \%, 0.067 \%$, and $0.126 \%$. While for $\alpha$ of $90^{\circ}$ to $30^{\circ}$, the strain ranges of the drastic $\mathrm{AE}$ events are $0.075 \%, 0.086 \%$, and $0.127 \%$. When the absolute value of $\alpha$ is same, the strain ranges of the drastic $\mathrm{AE}$ events of the double-hole defective rocks are also approximately equally with each other. The strain range of the serious $\mathrm{AE}$ events of the defective rocks when $\alpha$ is positive is wider than that of the defective rocks when $\alpha$ is negative.

\section{Damage Evolution Law of Rocks with Double-Hole Defects}

4.1. Damage Model Based on AE Events. There are a lot of parameters that can be used to define the damage variable $(D)$, such as cracks [25], elastic coefficient [26], yield stress [27], elongation [28], $\mathrm{AE}[29,30]$, energy [31], etc. In this study, $D$ is defined by the parameters of AE events as follows:

$$
D=\frac{N_{t}}{N}
$$

where $N_{\mathrm{t}}$ is the total AE events number of the rock material from the original point to a specific time, and $N$ is the total $\mathrm{AE}$ events number of the rock material when it failures completely.

Owing to that it is hard to judge if a specimen has been damaged completely during an experiment, the damage variable needs to be modified [32] and the modified damage variable can be expressed as

$$
D=k \frac{N_{\mathrm{t}}}{N},
$$



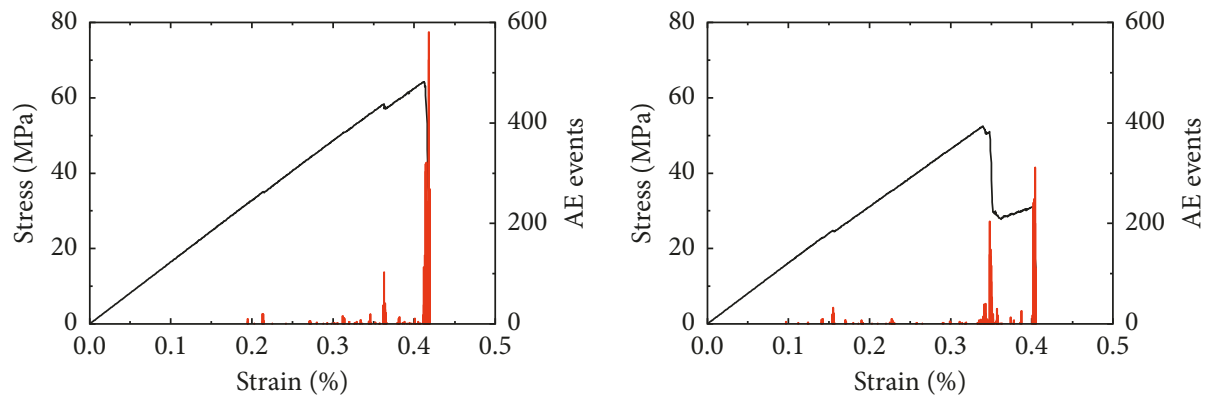

- Stress

AE Hits

Stres

AE Hits

(a)

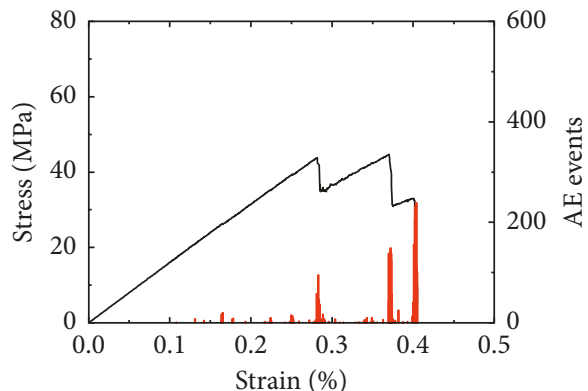

- Stress

AE Hits

(c)

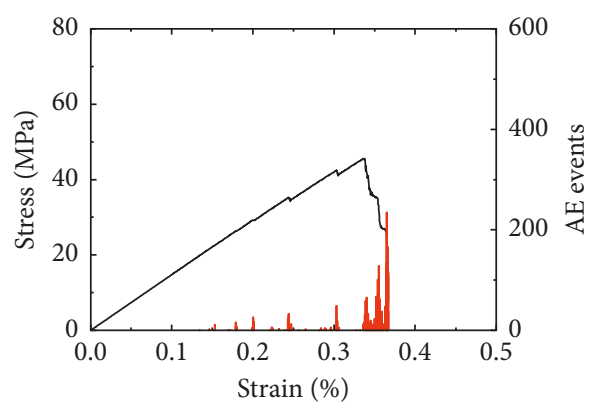

- Stress

AE Hits

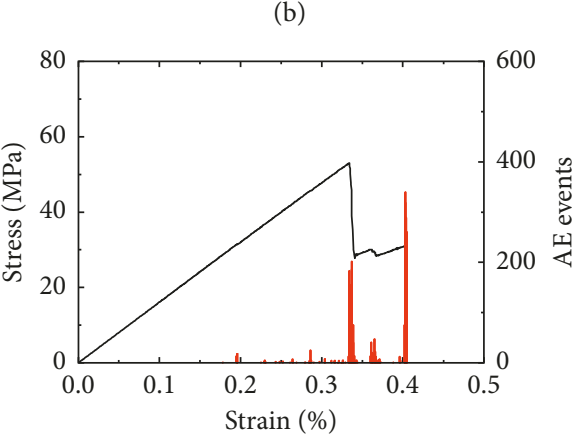

Stress

AE Hits

(d)

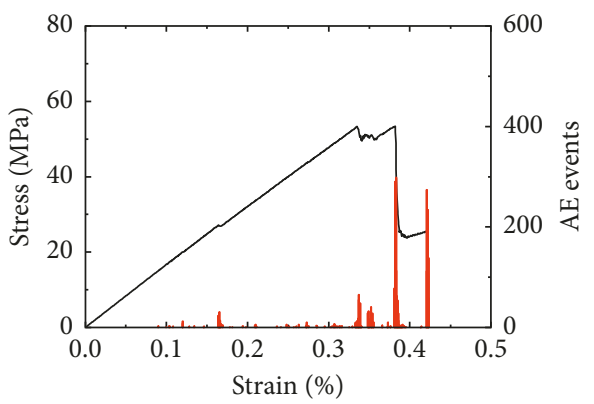

- Stress

AE Hits

(e)

(f)

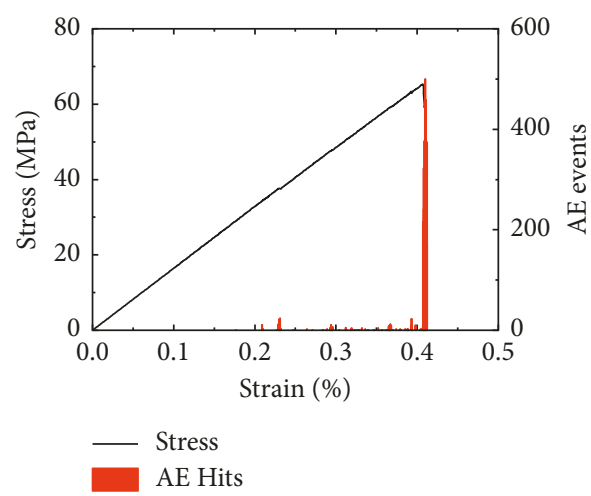

(g)

FigURE 10: Stress-strain-AE events curves of numerical double-hole defective rocks with different $\alpha$. (a) $\alpha=-90^{\circ}$, (b) $\alpha=-60^{\circ}$, (c) $\alpha=-30^{\circ}$, (d) $\alpha=0^{\circ}$, (e) $\alpha=30^{\circ}$, (f) $\alpha=60^{\circ}$, and (g) $\alpha=90^{\circ}$. 
where $k$ is the damage critical value and it can be normalized as

$$
k=1-\frac{\sigma_{\mathrm{r}}}{\sigma_{\mathrm{p}}},
$$

where $\sigma_{\mathrm{r}}$ is the residual strength of the rock material and $\sigma_{\mathrm{p}}$ is the peak strength. In this study, the tests will be end when the residual strength of the rock models is $10 \%$ of the peak strength, so the $k$ is equal to 0.9 .

Based on the $\mathrm{AE}$ events characteristics and strain equivalence principle $[19,33]$, the damage model of the rock model under uniaxial compression condition is established as shown in Equation (4).

$$
\sigma=E \mathcal{E}(1-D)=E \mathcal{E}\left[1-\left(1-\frac{\sigma_{\mathrm{r}}}{\sigma_{\mathrm{p}}}\right) \frac{N_{\mathrm{t}}}{N}\right] .
$$

Figure 11 shows the stress-strain curve fitted by Equation (4) and the numerical test result. It can be seen that for the rock materials, the damage constitutive model based on AE events characteristics can well reflect the stress-strain evolution characteristics.

\subsection{Characteristics of Damage Evolution of Double-Hole} Defective Rocks. Figure 12 describes the damage variablestrain curves of double-hole defective rocks with different $\alpha$. The damage variable-strain curve can also be divided into three stages according to the classification of the stress-strain curves. The first stage is corresponding with the elastic stage of the stress-strain curve. In this stage, there is no damage occurring and the stage can be named zero damage stage. The second stage is corresponding with the plastic stage of the stress-strain stage. In this stage, the damage increases gradually and the stage can be named stable evolution stage. The third stage is corresponding with the failure stage of the stress-strain curve. In this stage, the damage increases rapidly and the stage can be named failure damage stage.

In these three stages, $\alpha$ has different influence on the characteristics of damage evolution of the double-hole defective rocks. In zero damage stage, $\alpha$ affects the strain range of zero damage. Along with decreasing of the absolute value of $\alpha$, the strain range of zero damage is decreasing firstly and then increasing. When $\alpha$ is less than or equal to $0^{\circ}$, the strain ranges are $0.196 \%, 0.098 \%, 0,108 \%$, and $0.179 \%$. While when $\alpha$ is bigger than $0^{\circ}$, the strain ranges are $0.177 \%, 0.091 \%$, and $0.136 \%$.

In the stable evolution stage, $\alpha$ affects the damage rate of the double-hole defective rocks. When the strain value is less than $0.242 \%$, with decreasing of the absolute value of $\alpha$, the damage rate shows a trend of increasing firstly and then decreasing. When the strain value is larger than $0.242 \%$, it shows an increasing trend except when $\alpha$ is $0^{\circ}$. Meanwhile, the damage variable-strain curves are fluctuated when $\alpha$ is different. The damage fluctuations of double-hole defective rocks when the absolute values of $\alpha$ equal to $30^{\circ}$ and $60^{\circ}$ are higher than that of rocks when the absolute values of $\alpha$ equal to $90^{\circ}$ and $0^{\circ}$.

In failure damage stage, the increase rates of damage of defective rocks are higher than that in the stable evolution

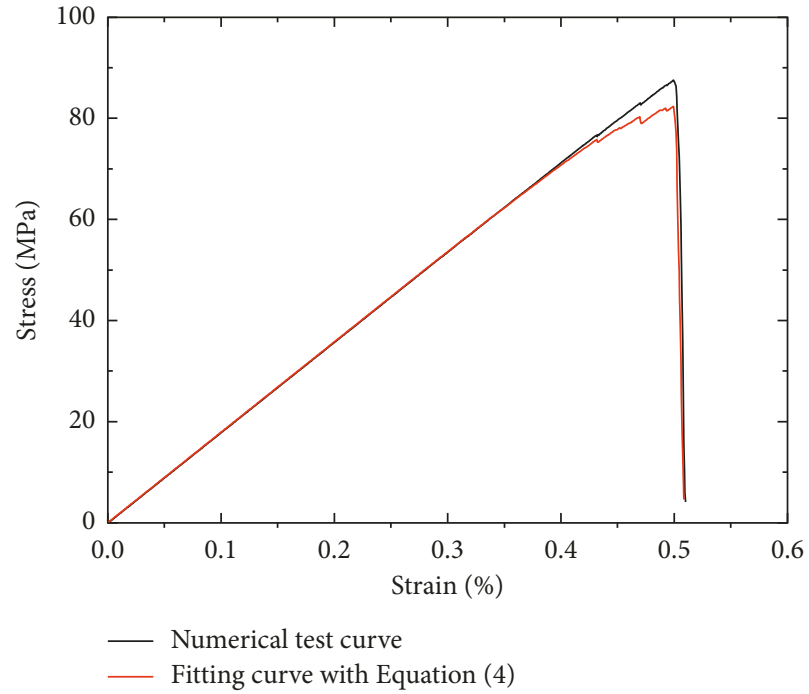

FIgURE 11: Stress-strain curves fitted by Equation (4) and the numerical test result.

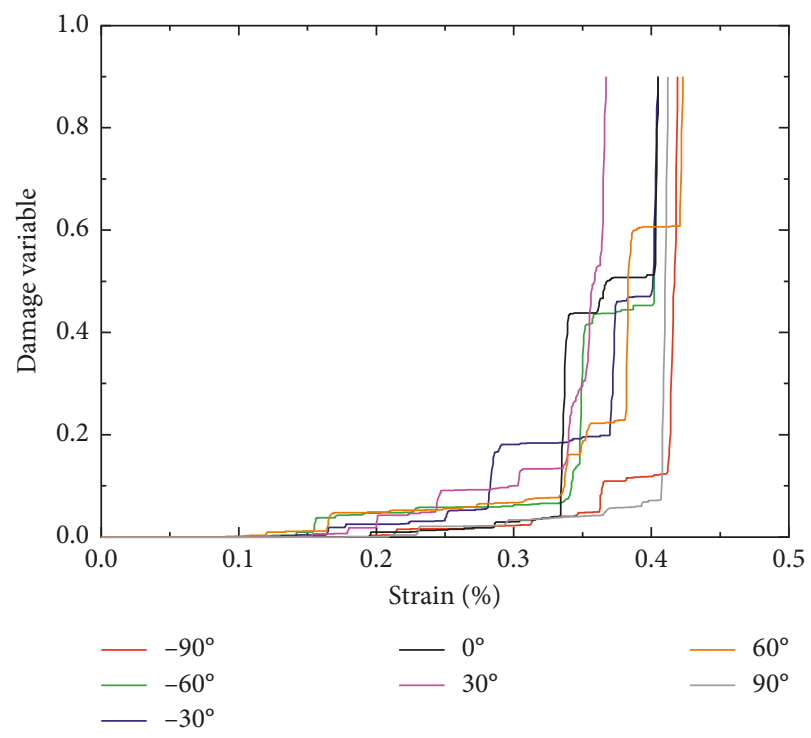

Figure 12: Damage variable-strain curves of double-hole defective rocks with different $\alpha$.

stage. $\alpha$ also affects the increasing rate of damage. Along with decreasing of the absolute value of $\alpha$, the damage rate is decreasing gradually. The slope is almost vertical when $\alpha$ is $90^{\circ}$ or $-90^{\circ}$.

\section{Conclusions}

In the study, the damage evolution characteristics of doublehole defective rock with different angles of the center connection line are studied systematically based on particle flow code. Several conclusions are obtained as the following.

The stress-strain behavior of the defective rock can be divided into the three stages of elastic, plastic and failure. The evolution characteristics of $\mathrm{AE}$ events and evolution laws of damage are closely related to the stress-strain relationship. 
According to the stress-strain curve, the damage variablestrain curve can be grouped zero damage stage, stable evolution stage, and failure damage stage.

With decrease of the absolute value of $\alpha$, the peak strength of the defective rocks is decreasing firstly and then increasing. The shape of the peak strength curve as $\alpha$ increasing from $-90^{\circ}$ to $90^{\circ}$ is a W type. The stress-strain characteristics are very discrete after peak strength. Along with the decreasing of the absolute value of $\alpha$, the post peak stress-strain curves changing from smoothness with one peak to fluctuate with several peaks. The failure modes of the double-hole defective rocks with the same absolute value of $\alpha$ are symmetrical to the horizontal axis or the longitudinal axis approximately. The main failure modes are oblique, $\mathrm{Y}$ type, $\mathrm{U}$ type, and $\mathrm{V}$ type when the absolute values of $\alpha$ are $90^{\circ}, 60^{\circ}, 30^{\circ}$ and $0^{\circ}$ respectively.

The influences of different center connection line angles on the characteristics of $\mathrm{AE}$ events include the maximum $\mathrm{AE}$ event number, the strain values of the initial $\mathrm{AE}$ event and the maximum $\mathrm{AE}$ event, and the strain range of the serious AE events. With the decreasing of the absolute value of $\alpha$, the maximum AE event number and the strain values of the initial $\mathrm{AE}$ event and the maximum $\mathrm{AE}$ event are decreasing, but the strain ranges of the serious $\mathrm{AE}$ events are increasing.

Different $\alpha$ has different influence on the characteristics of damage evolution of the double-hole defective rocks. In zero damage stage, $\alpha$ affects the strain range of zero damage. With decreasing of the absolute value of $\alpha$, the strain ranges of zero damage are decreasing firstly and then increasing. In the stable evolution stage, $\alpha$ affects the damage rate of the double-hole defective rocks. When the strain value is less than $0.242 \%$, with decreasing of the absolute value of $\alpha$, the damage rate shows a trend of increasing firstly and then decreasing. When the strain value is larger than $0.242 \%$, it shows an increasing trend except when $\alpha$ is $0^{\circ}$. In failure damage stage, the damage rates of defective rocks are higher than the stable evolution stage. With decreasing of the absolute value of $\alpha$, the damage rates are decreasing gradually. The slope is almost vertical when $\alpha$ is $90^{\circ}$ or $-90^{\circ}$.

\section{Data Availability}

We declare that all the data used to support the findings of this study are available from the corresponding author upon request.

\section{Conflicts of Interest}

The authors declare that they have no conflicts of interest.

\section{Acknowledgments}

This study is supported partially by National Natural Science Foundation of China (Grant nos. 41602300 and 51704179), Natural Science Foundation of Jiangsu Province (BK20150618), Open Research Foundation of the State Key Laboratory for Geomechanics and Deep Underground Engineering, China University of Mining and Technology (SKLGDUEK1503), Natural Science Foundation of
Shandong Province (ZR2016EEB23), Science and Technology Program of Shandong Province University (J15lh02), the Priority Academic Program Development of Jiangsu Higher Education Institutions (CE01-3-7), and the Key Research and Development Project of Shandong Province.

\section{References}

[1] S. Mahdevari, K. Shahriar, M. Sharifzadeh, and D. D. Tannant, "Stability prediction of gate roadways in longwall mining using artificial neural networks," Neural Computing and Applications, vol. 28, no. 11, pp. 3537-3555, 2017.

[2] W. P. Huang, C. Li, L. W. Zhang, Q. Yuan, Y. S. Zheng, and Y. Liu, "In situ identification of water-permeable fractured zone in overlying composite strata," International Journal of Rock Mechanics and Mining Sciences, vol. 105, pp. 85-97, 2018.

[3] C. Zhu, Z. G. Tao, S. Yang, and S. Zhao, "V shaped gully method for controlling rockfall on high-steep slopes in China," Bulletin of Engineering Geology and the Environment, pp. 1-17, 2018.

[4] B. Park and K. B. Min, "Bonded-particle discrete element modeling of mechanical behavior of transversely isotropic rock," International Journal of Rock Mechanics and Mining Sciences, vol. 76, pp. 243-255, 2015.

[5] S. Yang, H. Ni, and S. Wen, "Spatial acoustic emission evolution of red sandstone during multi-stage triaxial deformation," Journal of Central South University, vol. 21, no. 8, pp. 3316-3326, 2014.

[6] J. L. Justo, E. Justo, J. M. Azañón, P. Durand, and A. Morales, "The use of rock mass classification systems to estimate the modulus and strength of jointed rock," Rock Mechanics and Rock Engineering, vol. 43, no. 3, pp. 287-304, 2010.

[7] H. Lee and S. Jeon, "An experimental and numerical study of fracture coalescence in pre-cracked specimens under uniaxial compression," International Journal of Solids and Structures, vol. 48, no. 6, pp. 979-999, 2011.

[8] X. Wang and L. G. Tian, "Mechanical and crack evolution characteristics of coal-rock under different fracture-hole conditions: a numerical study based on particle flow code," Environmental Earth Sciences, vol. 77, no. 8, 2018.

[9] C. G. Sammis and M. F. Ashby, "The failure of brittle porous solids under compressive stress states," Acta Metallurgica, vol. 34, no. 3, pp. 511-526, 1986.

[10] B. V. D. Steen, A. Vervoort, and J. A. L. Napier, "Observed and simulated fracture pattern in diametrically loaded discs of rock material," International Journal of Fracture, vol. 131, no. 1, pp. 35-52, 2005.

[11] D. Li, T. Cheng, T. Zhou, and X. Li, "Experimental study of the dynamic strength and fracturing characteristics of marble specimens with a single hole under impact loading," Chinese Journal of Rock Mechanics and Engineering, vol. 34, no. 2, pp. 249-260, 2015, in Chinese.

[12] G. Han, H. W. Jing, H. Su, and J. Wu, "Experimental study on compressive strength and fracture characteristics of sandstone containing double circular cavities," Journal of the China Coal Society, vol. 42, no. 4, pp. 871-878, 2017, in Chinese.

[13] Y. Jiang, Y. Tanabashi, B. Li, and J. Xiao, "Influence of geometrical distribution of rock joints on deformational behavior of underground opening," Tunnelling and Underground Space Technology, vol. 21, no. 5, pp. 485-491, 2006.

[14] P. A. Cundall and O. D. Strack, "A discrete numerical model for granular assemblies," Geotechnique, vol. 29, no. 1, pp. 47-65, 1979. 
[15] Itasca Consulting Group, Inc., PFC2D (Particle Flow Code in 2 Dimensions), Itasca Consulting Group, Inc., Minneapolis, MN, USA, 2018, http://www.itascacg.com/software/ $\mathrm{pfc}$.

[16] D. W. Yin, S. J. Chen, X. Q. Liu, and H. F. Ma, "Effect of joint angle in coal on failure mechanical behavior of roof rock-coal combined body," Quarterly Journal of Engineering Geology and Hydrogeology, vol. 51, no. 2, pp. 202-209, 2018.

[17] N. Cho, C. D. Martin, and D. C. Sego, "A clumped particle model for rock," International Journal of Rock Mechanics and Mining Sciences, vol. 44, no. 7, pp. 997-1010, 2007.

[18] J. F. Hazzard, R. P. Young, and S. C. Maxwell, "Micromechanical modeling of cracking and failure in brittle rocks," Journal of Geophysical Research, vol. 105, no. B7, pp. 1668316697, 2000.

[19] Z. Wen, X. Wang, L. Chen, G. Lin, and H. Zhang, "Size effect on acoustic emission characteristics of coal-rock damage evolution," Advances in Materials Science and Engineering, vol. 2017, Article ID 3472485, 8 pages, 2017.

[20] W. Liu, Z. Yin, A. Yuan, and C Li, "Particle-discrete-elementmethod-based research on acoustic emission characteristics and energy evolution laws of surrounding rock in different lithologic roadway," Journal of Mining and Safety, vol. 34, no. 2, pp. 363-370, 2017, in Chinese.

[21] H. Su, C. Dang, and Y. Li, "Study of numerical simulation of acoustic emission in rock of inhomogeneity," Rock and Soil Mechanics, vol. 32, no. 6, pp. 1886-1890, 2011, in Chinese.

[22] U. Castro-Filgueira, L. R. Alejano, J. Arzúa, and D. M. Ivars, "Sensitivity analysis of the micro-parameters used in a PFC analysis towards the mechanical properties of rocks," Procedia Engineering, vol. 191, pp. 488-495, 2017.

[23] Q. Zhang, H. Zhu, L. Zhang, and X. Ding, "Study of scale effect on intact rock strength using particle flow modeling," International Journal of Rock Mechanics and Mining Sciences, vol. 48, no. 8, pp. 1320-1328, 2011.

[24] Q. Zhang, H. Zhu, and L. Zhang, "Studying the effect of nonspherical micro-particles on Hoek-Brown strength parameter mi using numerical true triaxial compressive tests," International Journal for Numerical and Analytical Methods in Geomechanics, vol. 39, no. 1, pp. 96-114, 2015.

[25] J. Kim, J. Yi, J. Kim, G. Zi, and J. S. Kong, "Fatigue life prediction methodology using entropy index of stress interaction and crack severity index of effective stress," International Journal of Damage Mechanics, vol. 22, no. 3, pp. 375-392, 2013.

[26] M. Mizuno, M. Okayasu, and N. Odagiri, "Damage evaluation of piezoelectric ceramics from the variation of the elastic coefficient under static compressive stress," International Journal of Damage Mechanics, vol. 19, no. 3, pp. 375-390, 2010.

[27] V. Murti, W. Zhang, and S. Valliappan, "Stress invariants in an orthotropic damage space," Engineering Fracture Mechanics, vol. 40, no. 6, pp. 985-990, 1991.

[28] S. Cao and X. Xian, "Testing study on the characteristics of creep and damage of coal and other rocks," Chinese Journal of Rock Mechanics and Engineering, vol. 20, no. 6, pp. 817-822, 2001, in Chinese.

[29] I. Iturrioz, G. Lacidogna, and A. Carpinteri, "Acoustic emission detection in concrete specimens: experimental analysis and lattice model simulations," International Journal of Damage Mechanics, vol. 23, no. 3, pp. 327-358, 2013.

[30] X. Wang, Z. J. Wen, Y. J. Jiang, and H. Huang, "Experimental study on mechanical and acoustic emission characteristics of rock-like material under non-uniformly distributed loads,"
Rock Mechanics and Rock Engineering, vol. 51, no. 3, pp. 729-745, 2018.

[31] X. S. Liu, J. G. Ning, Y. L. Tan, and Q. H. Gu, "Damage constitutive model based on energy dissipation for intact rock subjected to cyclic loading," International Journal of Rock Mechanics and Mining Sciences, vol. 85, pp. 27-32, 2016.

[32] Y. Zong, L. Han, J. Wei, and S. Wen, "Mechanical and damage evolution properties of sandstone under triaxial compression," International Journal of Mining Science and Technology, vol. 26, no. 4, pp. 601-607, 2016.

[33] J. Lemaitre, J. Sermage, and R. Desmorat, "A two scale damage concept applied to fatigue," International Journal of Fracture, vol. 97, no. 1-4, pp. 67-81, 1999. 


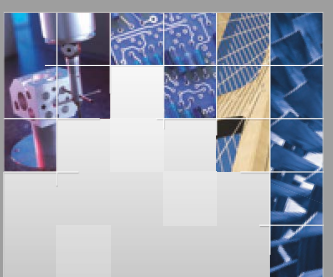

\section{Enfincering}
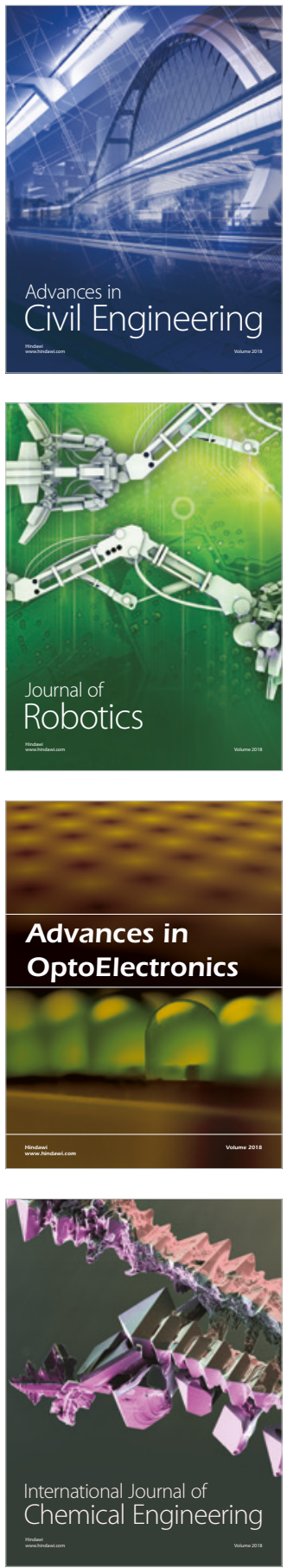

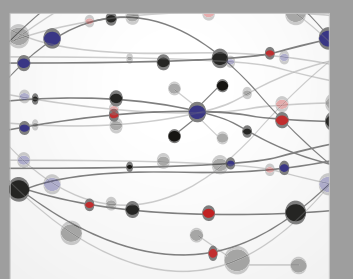

\section{Rotating \\ Machinery}

The Scientific World Journal

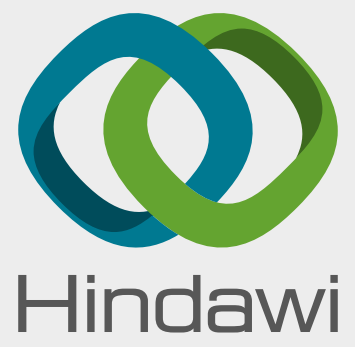

Submit your manuscripts at

www.hindawi.com
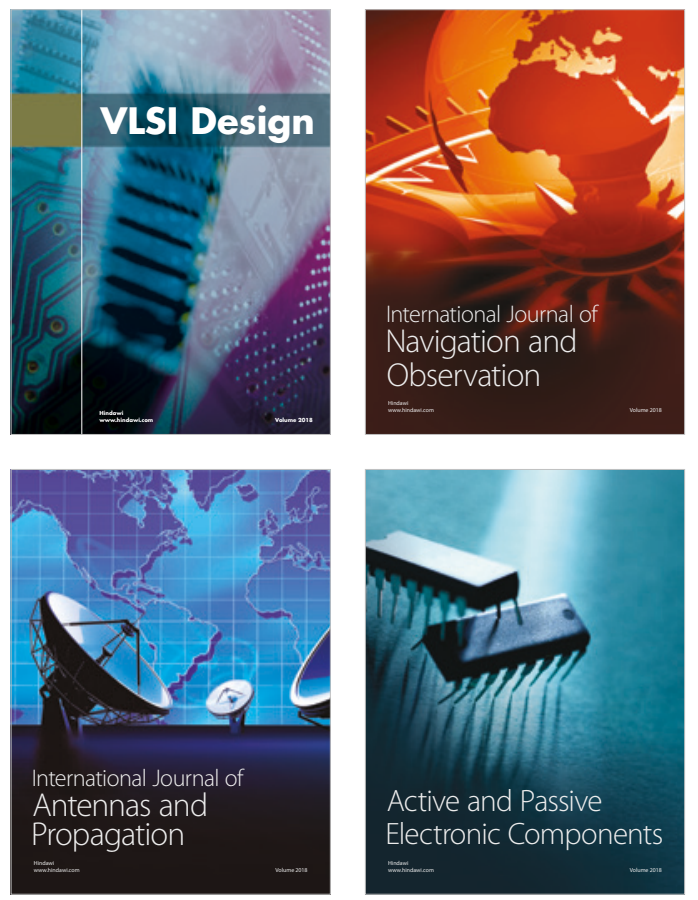
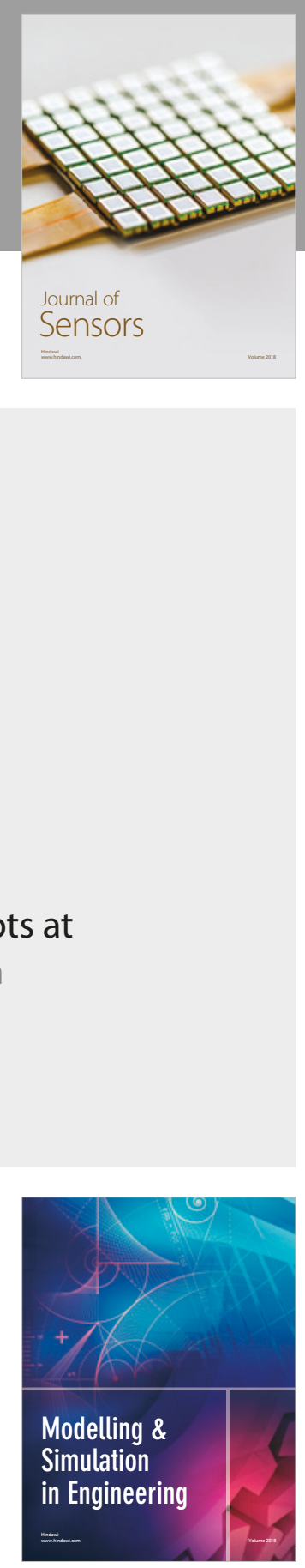

\section{Advances \\ Multimedia}
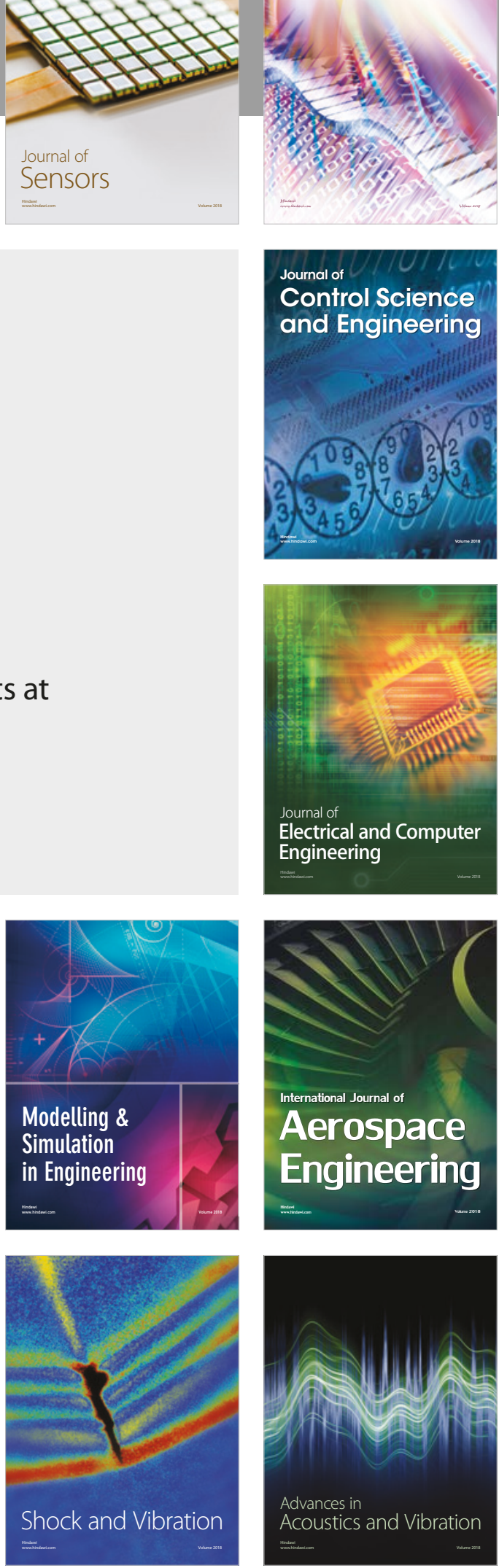